\title{
Serological study of Neospora caninum in dogs and wildlife in a nature conservation area in southern Portugal
}

\author{
H. WAAP ${ }^{1}$, T. NUNES ${ }^{2}, \mathrm{Y} . \mathrm{VAZ}^{2}$ and A. LEITÃO ${ }^{2} *$ \\ ${ }^{1}$ Laboratório de Parasitologia, Instituto Nacional de Investigação Agrária e Veterinária, Quinta do Marquês, 2780-157 \\ Oeiras, Portugal \\ ${ }^{2}$ CIISA, Faculdade de Medicina Veterinária, Universidade de Lisboa, Av. da Universidade Técnica, 1300-447 Lisboa, \\ Portugal
}

(Received 7 December 2016; revised 4 April 2017; accepted 20 May 2017)

\begin{abstract}
SUMMARY
A serological survey was performed to evaluate the presence of specific antibodies against Neospora caninum in dogs and native animals in a wildlife conservation area in southern Portugal. The study involved 463 animals, including dogs $(n=$ 286), European rabbits (Oryctolagus cuniculus; $n=32$ ), Egyptian mongoose (Herpestes ichneumon; $n=34)$, wild boars (Sus scrofa; $n=26$ ), foxes (Vulpes vulpes, $n=25)$, common genets (Genetta genetta; $n=17)$, red deer (Cervus elaphus; $n=14)$, wildcats (Felis silvestris; $n=6)$, four mustelid species $(n=17)$ and rodents $(n=6)$. Samples from dogs were analysed by Indirect Fluorescent Antibody Test (IFAT). Samples from wild animals were screened by the modified agglutination test and positive and doubtful results were confirmed by IFAT. The seroprevalence of N. caninum in dogs was $32.5 \%$ [95\% confidence interval (95\% CI) $27 \cdot 3-38 \cdot 1]$. Among wild animals, exposure to $N$. caninum was confirmed only in foxes $(12 \%, 95 \%$ CI $4 \cdot 2-30)$ and rabbits $(25 \%, 95 \%$ CI $13 \cdot 3-42 \cdot 1)$. This is the first evidence of natural exposure to $N$. caninum in foxes and rabbits in Portugal, and our results suggest that rabbits may play a role as reservoirs of infection to dogs, foxes and other wildlife carnivores. The relevance of this finding in the sylvatic cycle of $N$. caninum needs further studies, since infection may affect wildlife species and cattle grazing in the same areas.
\end{abstract}

Key words: Neospora caninum, dogs, rabbits, foxes, wildlife, seroprevalence.

\section{INTRODUCTION}

Neospora caninum is an obligate intracellular cystforming coccidian parasite with a worldwide distribution. Neospora caninum is a major cause of abortion in cattle and causes severe neuromuscular disease in dogs (Dubey, 2003; McInnes et al. 2006). The disease is responsible for considerable economic losses to the beef and dairy industries, which are mainly linked to the lower reproductive performance of affected cattle (Thurmond and Hietala, 1997; Dubey, 2003), but also to reduced milk production, premature culling and decreased weight gain (Thurmond and Hietala, 1996; Barling et al. 2000; Hernandez et al. 2001). Prevalence rates determined in seroepidemiological studies carried out at farm level may reach 100\% (Dubey, 1999).

Neospora caninum has a heteroxenous prey-predator life cycle. The definitive carnivorous host (DH) sheds unsporulated oocysts into the environment following predation of intermediate hosts (IH) containing $N$. caninum tissue cysts and IH become infected after ingestion of sporulated oocysts in

* Corresponding author: Laboratório de Parasitologia, Instituto Nacional de Investigação Agrária e Veterinária, Quinta do Marquês, 2780-157 Oeiras, Portugal; CIISA, Faculdade de Medicina Veterinária, Universidade de Lisboa, Av. da Universidade Técnica, 1300-447 Lisboa, Portugal. E-mail: helga.waap@iniav.pt, alexandre@fmv. ulisboa.pt water or food, or in the case of carnivores and omnivores, also through the consumption of infected tissues. In addition, $N$. caninum can be transmitted transplacentally in several host species (Dubey, 2003). Up to now, the only confirmed DH are canids from the genus Canis, namely dogs (Canis familiaris) (McAllister et al. 1998), coyotes ( $C$. latrans) (Gondim et al. 2004b), dingoes (C. lupus dingo) (King et al. 2010) and grey wolves (C. lupus lupus) (Dubey et al. 2014).

A wide range of domestic and wildlife species were shown to be susceptible to $N$. caninum infection, but their role in domestic and sylvatic transmission cycles still needs to be elucidated (Almería, 2013). Little is known about clinical neosporosis in wildlife. Disease in non-domestic carnivores was described only in a European pine marten and in blue and red foxes, in young animals, with similar neurological and dermatological presentations as in domestic dogs (Donahoe et al. 2015). Neospora caninum infection in artiodactyls is associated with stillbirths and systemic disease in very young animals (Donahoe et al. 2015).

Dogs become infected when fed with unfrozen, raw or undercooked beef. Other possible infection sources include feeding on abortion tissues from bovines, predation of small wildlife mammals and feeding on animal carcasses or offal from game animals left in the field (Gondim et al. 2004a). Though transplacental infection is considered the 
main mechanism for parasite transmission in cattle, the presence of dogs as a source of environmental contamination with oocysts, was found to be crucial to maintain the life cycle (Dubey, 2003; Dubey et al. 2007). Dogs should therefore be regarded as a potential risk factor, not only for cattle but also for natural populations sharing the same habitat. In Portugal, this is especially important in regards to nature conservation areas located in the region Alentejo, which has the largest inventory of grass-fed, extensively raised cattle in the country. Neospora caninum was identified for the first time as a cause of abortion in Portuguese cattle farms in 2001 (Thompson et al. 2001) and isolated from an aborted fetus in 2002 (Canada et al. 2002). Subsequent studies in intensive dairy farms, showed a prevalence of $28 \%$ in randomly sampled farms and $46 \%$ in farms with abortion problems (Canada et al. 2004).

The serological screening of $N$. caninum in dogs is an indirect means to evaluate environmental contamination, since seropositive animals probably already shed oocysts. The prevalence of antibodies to $N$. caninum in wildlife will mirror the impact of environmental contamination and reflect the susceptibility of native IH species to infection, therefore providing further evidence on the circulation of $N$. caninum between domestic and wild ecosystems (Almería, 2013).

This study aimed to evaluate the exposure to $N$. caninum in dogs and wild animals in a wildlife conservation area in the southeast of Portugal.

\section{MATERIALS AND METHODS}

\section{Sample characterization}

Serological tests were performed on serum samples from 286 dogs and serum $(n=126)$ and lung extracts $(n=51)$ from 177 wild animals. Wildlife species included 32 European rabbits (Oryctolagus cuniculus), 34 Egyptian mongoose (Herpestes ichneumon), 26 wild boars (Sus scrofa), 25 foxes (Vulpes vulpes), 17 common genets (Genetta genetta), 14 red deer (Cervus elaphus), six wildcats (Felis silvestris), six stone martens (Martes foina), six wildcats $(F$. silvestris), six European badgers (Meles meles), two European otters (Lutra lutra), six European polecats (Mustela putorius), one garden dormouse (Eliomys quercinus), one common rat (Rattus norvegicus), three western Mediterranean mice (Mus spretus) and one wood mouse (Apodemus sylvaticus). Sampling was performed between 2010 and 2013 in the frame of the project LIFE Habitat Lince Abutre (LIFE08 NAT/P/000227). Samples were obtained in a wildlife conservation area in the southeast of Portugal involving a total of 24 freguesias (the smallest administrative unit in Portugal) belonging to 13 municipalities in the NUTS2 regions
Alentejo and Algarve (Fig. 1). The sampling area is largely characterized by a peneplain landscape, generally not exceeding $200 \mathrm{~m}$ above sea level. The climate is typically Mediterranean Csa (Köppen climate classification), with warm to hot, dry summers and mild to cool, wet winters. Average monthly temperatures are above $22.0^{\circ} \mathrm{C}$ during the warmest month and range between 18 and $-3{ }^{\circ} \mathrm{C}$ in the coldest month (Kottek et al. 2006), while the average precipitation is $<800 \mathrm{~mm}$ per year (www. ipma.pt). Data on sex, age and sampling conditions of wildlife species (captured/hunted/road kill animals) were recorded whenever possible. Samples were sent to the National Institute for Veterinary and Agrarian Research (INIAV) for the diagnosis of several diseases that may affect the Iberian lynx and black vulture populations in this particular area. Samples and animal data were kindly provided for the purposes of this study by the national veterinary authority Direcção-Geral de Alimentação e Veterinária (DGAV).

\section{Neospora caninum production and purification}

Neospora caninum tachyzoites used to prepare the antigen suspension for the $N$. caninum modified agglutination test (N-MAT) and to coat Indirect Fluorescent Antibody Test (IFAT) slides were propagated by continuous passage in Vero cell (African Green Monkey kidney epithelial cells) cultures using Dulbecco's Minimal Essential Medium (DMEM) supplemented with $100 \mathrm{UI} \mathrm{mL}^{-1}$ penicillin, 100 $\mu \mathrm{g} \mathrm{mL}{ }^{-1}$ streptomycin, $2 \mathrm{~mm}$ l-glutamine, $20 \mathrm{~mm}$ HEPES and fetal calf serum (10\% to initiate cultures and $2 \%$ for maintenance) at $37{ }^{\circ} \mathrm{C}$ in closed $75 \mathrm{~cm}^{2}$ cell culture flasks. Tachyzoites were harvested after 3-4 days of infection. At this stage, most of the cell layer was confluent and $N$. caninum tachyzoites intracellular. The cell monolayer was scraped from the cell culture flask into the supernatant and the resulting suspension was passed through a $21 \mathrm{G}$ syringe to release tachyzoites from cells, centrifuged at $770 \mathrm{~g}$ for $15 \mathrm{~min}$, at $4{ }^{\circ} \mathrm{C}$, and the pellet was resuspended in phosphate-buffered saline (PBS). Tachyzoites were separated from host cell debris, using columns made of Whatman CF 11 cellulose powder, as described by Dempster (1984). The purified parasites were used immediately for $\mathrm{N}$ MAT antigen or IFAT slide preparation.

\section{$N-M A T$ antigen and IFAT slide preparation}

The N-MAT antigen was prepared as described by Packham et al. (1998) with minor changes (Waap et al. 2011). Briefly, cell-free parasites were washed once in $20 \mathrm{~mL}$ PBS and the pellet was resuspended in $2-3 \mathrm{~mL}$ of $37 \%$ formaldehyde diluted in PBS to $6 \%$ formaldehyde. Parasites were fixed overnight at $4{ }^{\circ} \mathrm{C}$ and then washed three times in $20 \mathrm{~mL}$ PBS to 


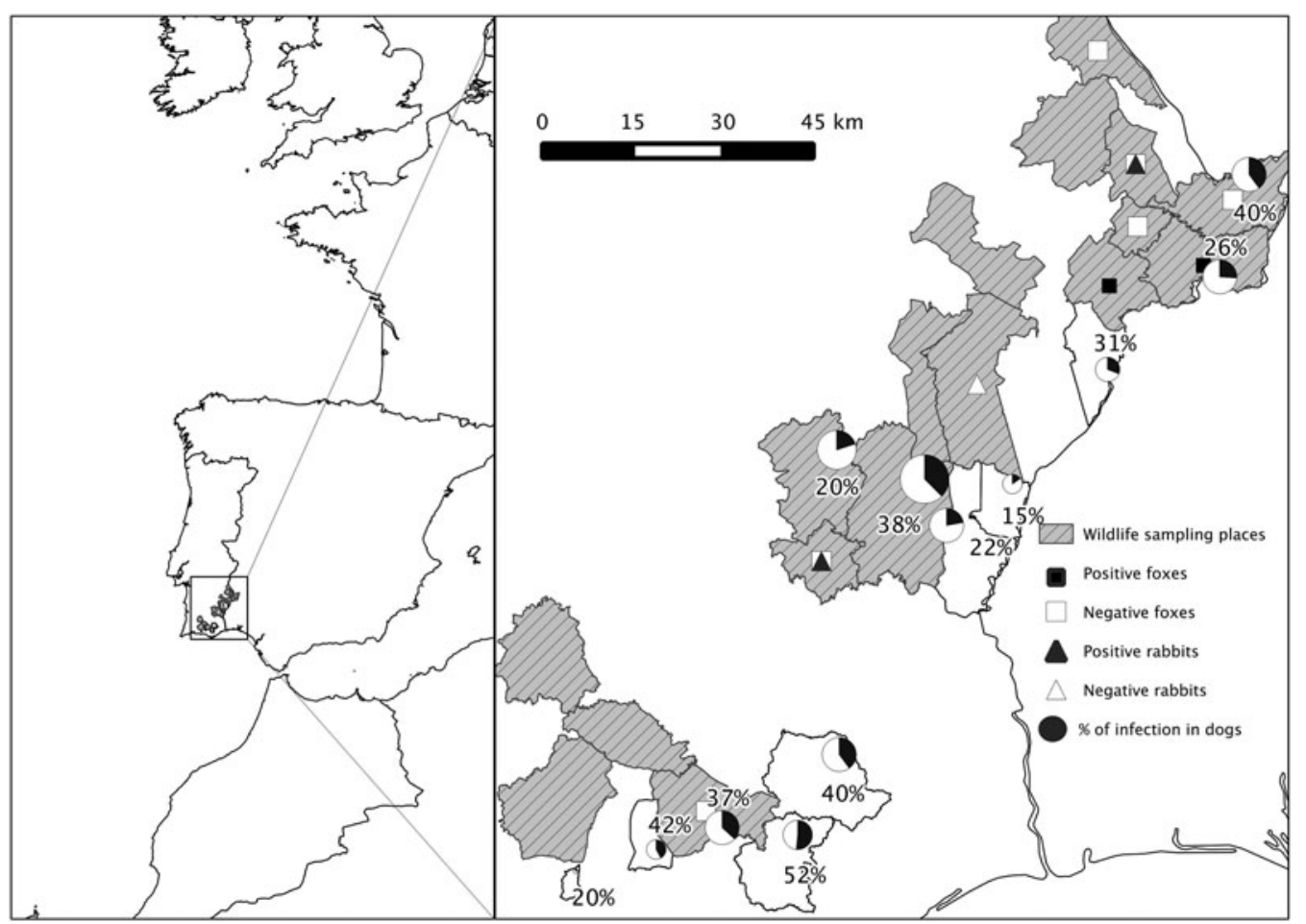

Fig. 1. Survey area: wildlife sampling places, sample prevalence of Neospora caninum in dogs and location of positive and negative foxes and rabbits. (C) EuroGeographics for the administrative boundaries.

remove formaldehyde. The fixed tachyzoites were counted on a Neubauer chamber and resuspended to a final concentration of $35-45 \times 10^{6}$ tachyzoites $\mathrm{mL}^{-1}$ in filtered $(0 \cdot 2 \mu \mathrm{M}$ pore size $)$ alkaline buffer (pH 8.7), containing 7.02 g NaCl, 3.09 $\mathrm{g} \mathrm{H}_{3} \mathrm{BO}_{3}$, $24 \mathrm{~mL} 1 \mathrm{~N} \mathrm{NaOH}, 50 \mathrm{mg}$ eosin $\mathrm{Y}, 1 \cdot 0 \mathrm{~g}$ sodium azide and $4 \mathrm{mg} \mathrm{mL}^{-1}$ bovine albumin (fraction $\mathrm{V}$ ) per litre.

IFAT slide preparation was based on the procedure proposed by Shkap et al. (2002). Briefly, purified tachyzoites were washed and suspended in a $4 \%$ formaldehyde solution in PBS, on ice, during $30 \mathrm{~min}$. The fixed tachyzoites were washed three times to remove formaldehyde and the pellet was suspended in $1 \mathrm{~mL}$ PBS. Parasites were counted and diluted in PBS to a final concentration of $2 \times 10^{6}$ tachyzoites $\mathrm{mL}^{-1}$, distributed in $6 \mu \mathrm{L}$ drops on slides, dried at $37^{\circ} \mathrm{C}$ and fixed in cold acetone $\left(-20^{\circ} \mathrm{C}\right)$ for $10 \mathrm{~min}$.

\section{Screening of anti-N. caninum-specific IgG antibodies in dogs}

Serum samples from dogs were screened for specific anti- $N$. caninum antibodies by the IFAT at three dilutions $(1: 50,1: 100$ and 1:200) using rabbit antidog IgG-FITC secondary antibody (Sigma Aldrich) diluted at 1:750 in 0.01\% Evans blue solution. Positive and negative IFAT controls (canine origin, VMRD, Inc) were included in each testing round. Bovine serum albumin was added to the serum and conjugate diluting buffers in order to reduce non-specific binding of antibodies. Slides were mounted with 50\% glycerol in PBS (pH 8.5) and viewed under a Zeiss fluorescence microscope with a $40 \times$ objective. Complete peripheral fluorescence was regarded as a positive reaction, while partial, apical or absent fluorescence was considered a negative reaction.

\section{Analysis of anti-N. caninum-specific IgG antibodies in wildlife species}

Lung tissue samples were collected during necropsy and processed as described by Ferroglio et al. (2000) to prepare lung extracts for serological analysis. Lung extracts were shown to be suitable for the screening of specific antibodies against several pathogens in wildlife, including Encephalitozoon (Waller et al. 1980), Francisella tularensis (Mörner et al. 1988), canine parvovirus (Duarte et al. 2012) and Toxoplasma gondii (Jakubek et al. 2012; Waap et al. 2016).

Serum samples and lung extracts were screened for $\mathrm{IgG}$ antibodies to $N$. caninum at 1:50, 1:150 and 1:450 dilutions using N-MAT according to previously established procedures (Packham et al. 1998). Each testing round included positive and negative control sera from cattle and dogs tested by IFAT and ELISA, as well as an antigen control (PBS instead of serum). Agglutination of tachyzoites as a diffuse opacity covering at least half of the well was considered a positive reaction and sedimentation as a button or ring a negative reaction. Positive and doubtful results, characterized by an indistinct agglutination pattern, were tested by the IFAT at 
1:50, 1:100 and 1:200 dilutions, in order to confirm the serological status of animals. Sera from foxes were assayed with rabbit antidog IgG-FITC secondary antibody (Sigma Aldrich) and rabbits were tested with donkey antirabbit IgG secondary antibody, Alexa Fluor 488 (Thermo Fisher Scientific). Proteins $A$ and $G$ can bind with strong affinity to immunoglobulin of several species and are commonly applied in ELISA tests for multi-species diagnosis (Zhang et al. 2010; Schaefer et al. 2011) Therefore, confirmation of positive and doubtful results in the other wildlife species was attempted with Alexa Fluor 488 proteins A and G conjugates (Thermo Fisher Scientific).

\section{Data analysis}

The $95 \%$ confidence intervals (CI) for prevalence data were calculated by Wilson's score method assuming a perfect test using EpiTools Epidemiological Calculator (Sergeant, 2016). Geographical distribution maps were constructed using Quantum Geographic Information System (QGIS) software 2.0.1.

\section{RESULTS}

The overall seroprevalence in dogs at the established cut-off of $1: 50$ was $32 \cdot 5 \%$ (CI $27 \cdot 3-38 \cdot 1$ ). Considering the three dilutions used for titration of sera, 22 dogs were positive at the cut-off dilution 1:50, $17 \mathrm{dogs}$ had an endpoint titre at 1:100 dilution and 54 had endpoint titres $\geq 1: 200$ (Table 1). Overall, reading of results at 1:50 dilution was difficult, due to considerable non-specific binding of antibodies, visible as a strong apical fluorescence, which frequently extended to more than half of the tachyzoite membranes.

In wildlife animals tested by the N-MAT, a distinct agglutination pattern indicating the presence of antibodies to $N$. caninum was observed in two foxes and 15 rabbits, while six rabbits, two foxes, two wild boars and two Egyptian mongoose were considered doubtful. Positive reactivity was only detected in sera; all lung extracts tested negative. Two foxes and one rabbit had an N-MAT endpoint titre at 1:50 dilution, and 14 rabbits had endpoint titres $\geq 1: 450$ (Table 1). Confirmation of N-MAT positive and doubtful results by IFAT showed the presence of antibodies to $N$. caninum in both positive foxes and eight seropositive rabbits, while one of the doubtful fox sera and one of the doubtful rabbit sera were also found to be positive. One fox and one rabbit had an IFAT titre of 1:50, two rabbits had a titre of 1:100 and two foxes and five rabbits had titres $\geq 200$ (Table 1). Seropositive foxes came from two out of eight freguesias sampled, and seropositive rabbits came from two out of three freguesias (Fig. 1). At the positive sampling sites, antibodies to $N$. caninum were found in 1 of 12 and 2 of 6 foxes and 3 of 12 and 5 of 17 rabbits. Positive foxes included one adult female and one juvenile and one subadult male. No data on sex and age were available for rabbits. Only animals with a positive reaction in both assays were considered seropositive; therefore, the percentage of infected individuals in the sample was considered to be $12 \%$ (CI $4 \cdot 2-30 \%$ ) in foxes and $25 \%$ (CI $13 \cdot 3-42 \cdot 1 \%)$ in rabbits. Evaluation of the protein $\mathrm{A} / \mathrm{G}$ system for confirmation of doubtful results in the two Egyptian mongoose and two wild

Table 1. Number $(n)$ of lung extracts (LE) and sera from dogs and wildlife animals tested, percentage of infection in the total sample (\%) and NAT and IFAT titres in confirmed results

\begin{tabular}{|c|c|c|c|c|c|c|c|c|c|c|}
\hline \multirow[b]{2}{*}{ Family } & \multirow[b]{2}{*}{ Species } & \multirow{2}{*}{$\begin{array}{l}\mathrm{LE} \\
(n)\end{array}$} & \multirow{2}{*}{$\begin{array}{l}\text { Sera } \\
(n)\end{array}$} & \multirow[b]{2}{*}{$\%$} & \multicolumn{3}{|c|}{ NAT titres } & \multicolumn{3}{|c|}{ IFAT titres } \\
\hline & & & & & $1: 50$ & $1: 150$ & $1: 450$ & $1: 50$ & $1: 100$ & $1: 200$ \\
\hline \multirow[t]{2}{*}{ Canidae } & Dog (Canis familiaris) & - & 286 & $32 \cdot 5$ & - & - & - & 22 & 17 & 54 \\
\hline & Fox (Vulpes vulpes) & 7 & 18 & $12 \cdot 0$ & 3 & 0 & 0 & 1 & 0 & 2 \\
\hline Leporidae & $\begin{array}{l}\text { European rabbit (Oryctolagus } \\
\text { cuniculus) }\end{array}$ & - & 32 & $25 \cdot 0$ & 1 & 0 & 14 & 1 & 2 & 5 \\
\hline Felidae & Wild cat (Felis silvestris) & 3 & 3 & 0 & & & & & & \\
\hline \multirow[t]{4}{*}{ Mustelidae } & European badger (Meles meles) & 6 & - & 0 & & & & & & \\
\hline & European otter (Lutra lutra) & 2 & - & 0 & & & & & & \\
\hline & Stone marten (Martes foina) & 2 & 4 & 0 & & & & & & \\
\hline & European polecat (Mustela putorius) & 2 & 1 & 0 & & & & & & \\
\hline Herpestidae & $\begin{array}{l}\text { Egyptian mongoose (Herpestes } \\
\text { ichneumon) }\end{array}$ & 5 & 29 & 0 & & & & & & \\
\hline Viverridae & Common genet (Genetta genetta) & 4 & 13 & 0 & & & & & & \\
\hline Suidae & Wild boar (Sus scrofa) & - & 26 & 0 & & & & & & \\
\hline Gliridae & Garden dormouse (Eliomys quercinus) & 1 & - & 0 & & & & & & \\
\hline \multirow[t]{3}{*}{ Muridae } & Common rat (Rattus norvegicus) & 1 & - & 0 & & & & & & \\
\hline & $\begin{array}{l}\text { Western Mediterranean mouse (Mus } \\
\text { spretus) }\end{array}$ & 3 & - & 0 & & & & & & \\
\hline & Wood mouse (Apodemus sylvaticus) & 1 & - & 0 & & & & & & \\
\hline Cervidae & Red deer (Cervus elaphus) & - & 14 & 0 & & & & & & \\
\hline
\end{tabular}


boar sera included titration of Alexa Fluor 488 proteins $A$ and $G$ conjugates (Thermo Fisher Scientific) and titration of control sera. The binding of the conjugate was assessed with $N$. caninum slides and positive and negative dog sera, and with $T$. gondii slides and positive and negative fox, pig, wild boar and Egyptian mongoose sera. However, except for dogs and foxes, the fluorescent signal was too weak to establish the seropositivity of sera (data not shown). Based on these results, the protein $A / G$ system was found to be unsuitable to confirm infection in Egyptian mongoose and wild boars and this species was therefore considered to be negative.

\section{ISCUSSION}

The aim of this study was to determine the presence of specific antibodies anti- $N$. caninum in samples from dogs and wild animals in a nature conservation area in the southeast of Portugal.

Several serological techniques have been employed to screen for anti- $N$. caninum antibodies in different animal species, including the IFAT, usually using the cut-off of 1:50 in dogs (Björkman and Uggla, 1999; Silva et al. 2007; Uzeda et al. 2007; Yakhchali et al. 2010; Robbe et al. 2016; Wang et al. 2016), the N-MAT and various ELISAs. The competitive cELISA and N-MAT are the most commonly used tests in wildlife, because these techniques do not require the use of species-specific secondary antibodies (Almería, 2013). Though the assay principle of the cELISA makes this test attractive to be used in all species, validation data are absent and several authors have stated a lack of test agreement with IFAT results (Capelli et al. 2006; Sobrino et al. 2008).

In this study, we opted to use the IFAT for the serological survey in dogs. The IFAT has been widely employed for $N$. caninum serology in dogs and is generally accepted as the reference test (Björkman and Uggla, 1999; Capelli et al. 2006; Silva et al. 2007). Several authors have also claimed that the IFAT is more specific than the ELISA, because the use of crude tachyzoite antigen as coating antigen in soluble extract-based ELISAs may be a cause of cross-reactivity with $T$. gondii and other related apicomplexan parasites (Björkman and Hemphill, 1998; Silva et al. 2007). Though many authors consider the dilution 1:50 the most appropriate cut-off for seropositivity in dogs (Björkman and Uggla, 1999; Silva et al. 2007; Uzeda et al. 2007; Yakhchali et al. 2010; Robbe et al. 2016; Wang et al. 2016), in this study, interpretation of results was difficult, with a high percentage of sera producing strong apical reactions, in many instances with incomplete peripheral fluorescence of fixed tachyzoites. Others, when using the IFAT for the serological screening of $N$. caninum in different species made similar observations (Paré et al. 1995; Mineo et al. 2001; Galvão et al. 2015). Apical, unspecific fluorescence may arise from serological cross-reactivity with other apicomplexan species (Paré et al. 1995), due to the presence of conserved apical complex antigens (Conrad et al. 1993). Nevertheless, according to other authors, the IFAT for $N$. caninum shows little cross-reactivity with frequent apicomplexan parasites of dogs, such as $T$. gondii, Sarcocystis spp., Babesia canis and Hammondia heydorni (Dubey and Lindsay, 1993; Trees et al. 1993; Dubey et al. 1996; Gondim et al. 2015), but the extent to which antibodies to other protozoa (e.g. Cystoisospora spp., Cryptosporidium spp.) may cross-react is unknown. Since reading of results depends on the subjective assessment of the observer, this emphasizes even more the need for reassessment of cut-offs and harmonization of IFAT reagents and slide preparation procedures.

Wildlife species were assayed by a serial testing strategy, using the N-MAT as the first screening assay and the IFAT to confirm results. The use of two tests to determine the infection status of wild animals is generally recommended, due to the lack of validated tests for wildlife species. The choice of the N-MAT was based on the higher sensitivity, compared with the IFAT, possibly resulting from a better exposure of epitopes of suspended whole formalin-fixed tachyzoites, while the IFAT has proven to be more specific (Packham et al. 1998).

Information on $N$. caninum prevalence in dogs in Portugal is available from only one study (Maia et al. 2014), which recorded an overall prevalence of $7 \cdot 9 \%$ in dogs by cELISA. The seroprevalence found in the regions Alentejo (5.5\%) and Algarve (8.8\%) was substantially lower than in the present survey. This may be explained by differences in sample size, time and place of sampling, as well as the serological screening assay used. Prevalence data from other European countries vary likewise substantially. Similar infection rates between 32 and $32.7 \%$ were recorded in Italy (Robbe et al. 2016) and Romania (Gavrea et al. 2012), and rates up to $43.6 \%$ were reported from Spain (Collantes-Fernández et al. 2008; Regidor-Cerrillo et al. 2010), while studies carried out in Austria (Wanha et al. 2005), Czech Republic (Václavek et al. 2007), Serbia (Kuruca et al. 2013) and Poland (Ploneczka and Mazurkiewicz, 2008; Goździk et al. 2011) found a lower prevalence, ranging between 4.9 and $21 \cdot 7 \%$.

Infection of dogs in both urban and rural environments is likely to occur through feeding on raw or poorly cooked beef, and vertical transmission from bitches to successive litters has also been described (Dubey et al. 2007). However, dogs in rural/nature conservation areas are more probable to predate potentially infected small mammals and birds and to have access to aborted fetal tissues from cattle and wild ruminants, carcasses from wild animals 
and hunting offal, which may explain the high infection rate found in the present survey.

Concerning the wildlife species tested in this study, anti- $N$. caninum-specific antibodies were detected only in foxes and rabbits. This is the first evidence of exposure to $N$. caninum in wild animals in Portugal. Unfortunately, it was not possible to establish a correlation between the seropositivity found in dogs, foxes and rabbits, mainly because most sampling areas of these species were not coincident. This may be explained by the difficulty to match the sampling from hunted, captured or road kill wild animals with the sampling from dogs in the same areas. Spatial analysis is also hampered by the low seroprevalence of $N$. caninum in wildlife and because some species of wild animals have a wide home range. Spatial analysis to correlate infection in dogs and wild animals will therefore require a greater geographical coverage and a more representative sample size. The percentage of infection found in foxes in the present study $(12 \%)$ is higher than that reported in most studies carried out in Europe. Thus, studies using the IFAT recorded infection rates between 0.9 and $4.4 \%$ in foxes in Britain (Hamilton et al. 2005), Czech Republic (Bártová et al. 2016), Ireland (Murphy et al. 2007) and Spain (Sobrino et al. 2008), while studies carried out by ELISA showed a prevalence of $1.5 \%$ in Hungary (Jakubek et al. 2007) and absence of infection among 221 foxes sampled in different parts of Sweden (Jakubek et al. 2001). However, in some areas, exposure of foxes to $N$. caninum may be high, as shown by the prevalence of $69 \cdot 8 \%$ determined by the N-MAT in the Spanish Pyrenees (Marco et al. 2008). Despite the seroprevalence and the occasional finding of $N$. caninum-like oocysts in feces, red foxes were not shown to be definitive hosts (Dubey et al. 2017). Nonetheless, a study on the feeding habits of foxes in Britain showed that foxes feed mainly on medium-sized mammals, primarily rabbits, corresponding to $74 \%$ of mass ingested (Baker et al. 2006), and there is evidence that foxes select rabbits when they are abundant, feeding on small mammals and fruits/seeds when lagomorphs are scarce (Díaz-Ruiz et al. 2013). The infection rate of $25 \%$ found in the present survey suggests therefore that rabbits could be the main source of infection with $N$. caninum to foxes and that fluctuation of the rabbit population may account for the variable seroprevalence found in different areas. In fact, though Almería et al. (2007) did not detect antibodies in any of 251 wild rabbits tested in Spain, rabbits were shown to be natural IH of $N$. caninum by molecular methods, with an infection prevalence of $10.5 \%$ (Hughes et al. 2008). In addition, antibodies to $N$. caninum were found in 1.2 and $1.85 \%$ of animals tested by the IFAT in rabbit farms in Northern Italy and Northern Egypt, respectively (Ibrahim et al. 2009;
Machacova et al. 2015). The lower prevalence in farmed rabbits can be explained by the fact that caged animals in industrial units have fewer opportunities to become infected with $N$. caninum oocysts.

Though seropositivity to $N$. caninum was described in several Mustelidae, Herpestidae, wild boars, wild cats and wild ruminants (Almería, 2013; Donahoe et al. 2015), none of these species in the present survey were positive. Since the prevalence of infection can be low, the number of animals analysed may not be representative enough and further investigations on these species are needed, in order to assess their role in the sylvatic cycle of $N$. caninum in the area studied.

\section{Conclusion}

Our results show a high prevalence $N$. caninum in dogs in a wildlife conservation area in Portugal and suggest that rabbits could be a reservoir of infection to dogs, foxes and other wildlife carnivores. The high seroprevalence in dogs and foxes at 1:50 dilution may be caused by a too low cut-off and should be interpreted carefully. Prevalence of $N$. caninum in dogs and wildlife will need to be taken into account to define adequate prevention measures to reduce transmission to cattle. Asides cattle management practices aimed at reducing vertical transmission in affected farms, prevention strategies should address more incisively horizontal transmission, i.e. discourage feeding dogs with fresh raw meat and restricting as much as possible the access of dogs to ruminants, calving areas and livestock feed and water. Additionally, hunters should take special care in regards to the safe disposal of tissues and organs from hunted animals, in order to prevent infection of dogs and wild carnivores.

\section{ACKNOWLEDGEMENTS}

The authors are grateful to project LIFE Habitat Lince Abutre (LIFE08 NAT/P/000227) for the samples used in this study and associated data, with special thanks to DGAV and Patrícia Tavares Santos. The authors also acknowledge Lucinda Marques and Maria do Carmo Ramos (INIAV/Parasitology Laboratory) for invaluable technical assistance.

FINANCIAL SUPPORT

This research received no specific grant from any funding agency, commercial or not-for-profit sectors.

CONFLICT OF INTEREST

None.

REFERENCES

Almería, S. (2013). Neospora caninum and Wildlife. ISRN Parasitology 2013, 947347 . 
Almería, S., Vidal, D., Ferrer, D., Pabón, M., Fernández-deMera, M. I., Ruiz-Fons, F., Alzaga, V., Marco, I., Calvete, C., Lavin, S., Gortazar, C., López-Gatius, F. and Dubey, J. P. (2007). Seroprevalence of Neospora caninum in non-carnivorous wildlife from Spain. Veterinary Parasitology 143, 21-28.

Baker, P., Furlong, M., Southern, S. and Harris, S. (2006). The potential impact of the red fox (Vulpes vulpes) predation in agricultural landscapes in lowland Britain. Wildlife Biology 12, 39-50.

Barling, K. S., McNeill, J. W., Thompson, J. A., Paschal, J. C., McCollum, F. T., Craig, T. M. and Adams, L. G. (2000). Association of serologic status for Neospora caninum with postweaning weight gain and carcass measurements in beef calves. Fournal of the American Veterinary Medical Association 217, 1356-1360.

Bártová, E., Slezáková, R., Nág1, I. and Sedlák, K. (2016). Neospora caninum and Toxoplasma gondii antibodies in red foxes (Vulpes vulpes) in the Czech Republic. Annals of Agricultural and Environmental Medicine 23, 84-86.

Björkman, C. and Hemphill, A. (1998). Characterization of Neospora caninum iscom antigens using monoclonal antibodies. Parasite Immunology 20, 73-80.

Björkman, C. and Uggla, A. (1999). Serological diagnosis of Neospora caninum infection. International fournal for Parasitology 29, 1497-1507. Canada, N., Meireles, C. S., Rocha, A., Sousa, S., Thompson, G., Dubey, J. P., Romand, S., Thulliez, P. and Correia da Costa, J. M. (2002). First Portuguese isolate of Neospora caninum from an aborted foetus from a dairy herd with endemic neosporosis. Veterinary Parasitology 110, 11-15.

Canada, N., Carvalheira, J., Meireles, C. S., Correia da Costa, J. M. and Rocha, A. (2004). Prevalence of Neospora caninum infection in dairy cows and its consequences for reproductive management. Theriogenology 62, 1229-1235.

Capelli, G., Natale, A., Nardelli, S., Frangipane di Regalbono, A. and Pietrobelli, M. (2006). Validation of a commercially available cELISA test for canine neosporosis against an indirect fluorescent antibody test (IFAT). Preventive Veterinary Medicine 73, 315-320.

Collantes-Fernández, E., Gómez-Bautista, M., Miró, G., AlvarezGarcía, G., Pereira-Bueno, J., Frisuelos, C. and Ortega-Mora, L. M. (2008). Seroprevalence and risk factors associated with Neospora caninum infection in different dog populations in Spain. Veterinary Parasitology 152, 148-151.

Conrad, P. A., Sverlow, K., Anderson, M., Rowe, J., BonDurant, R., Tuter, G., Breitmeyer, R., Palmer, C., Thurmond, M., Ardans, A., Dubey, J. P., Duhamel, G. and Barr, B. (1993). Detection of serum antibody responses in cattle with natural or experimental Neospora infections. Fournal of Veterinary Diagnostic Investigation 5, 572-578.

Dempster, R. P. (1984). Toxoplasma gondii: purification of zoites from peritoneal exudates by eight methods. Experimental Parasitology 57, 195-207. Díaz-Ruiz, F., Delibes-Mateos, M., García-Moreno, J. L., LópezMartín, J. M., Ferreira, C. and Ferreras, P. (2013). Biogeographical patterns in the diet of an opportunistic predator: the red fox Vulpes vulpes in the Iberian Peninsula. Mammal Review 43, 59-70.

Donahoe, S. L., Lindsay, S. A., Krockenberger, M., Phalen, D. and Šlapeta, J. (2015). A review of neosporosis and pathologic findings of Neospora caninum infection in wildlife. International fournal for Parasitology: Parasites and Wildlife. 4, 216-238.

Duarte, A., Fernandes, M., Santos, N. and Tavares, L. (2012). Virological Survey in free-ranging wildcats (Felis silvestris) and feral domestic cats in Portugal. Veterinary Microbiology 158, 400-404

Dubey, J. P. (1999). Neosporosis in cattle: biology and economic impact. Fournal of the American Veterinary Medical Association 214, 1160-1162.

Dubey, J. P. (2003). Review of Neospora caninum and neosporosis in animals. Korean fournal of Parasitology 41, 1-16.

Dubey, J. P. and Lindsay, D. S. (1993). Neosporosis. Parasitology Today 9, 452-458.

Dubey, J. P., Lindsay, D. S., Adams, D. S., Gay, J. M., Baszler, T. V., Blagburn, B. L. and Thulliez, P. (1996). Serologic responses of cattle and other animals infected with Neospora caninum. American Fournal of Veterinary Research 57, 329-336.

Dubey, J. P., Schares, G. and Ortega-Mora, L. M. (2007). Epidemiology and control of neosporosis and Neospora caninum. Clinical Microbiology Reviews 20, 323-367.

Dubey, J. P., Jenkins, M. C., Ferreira, L. R., Choudhary, S., Verma, S. K. and Kwok, O. C. (2014). Isolation of viable Neospora caninum from brains of wild gray wolves (Canis lupus). Veterinary Parasitology 201, 150-153. Dubey, J. P., Hemphill, A., Calero-Bernal, R. and Schares, G. (2017). Neosporosis in Wild Canids and Other Carnivores. In Neosporosis in animals (ed. Dubey, J. P., Hemphill, A., Calero-Bernal, R. and Schares, G.) pp. 379-389. CRC Press, Boca Raton, Florida, USA.
Ferroglio, E., Rossi, L. and Gennero, S. (2000). Lung-tissue extract as an alternative to serum for surveillance for brucellosis in chamois. Preventive Veterinary Medicine 43, 117-122.

Galvão, C. M., Rezende-Gondim, M. M., Chaves, A. C., Schares, G., Ribas, J. R. and Gondim, L. F. (2015). Brazilian donkeys (Equus asinus) have a low exposure to Neospora spp. Brazilian Fournal of Veterinary Parasitology 24, 340-344

Gavrea, R., Mircean, V., Pastiu, A. and Cozma, V. (2012). Epidemiological survey of Neospora caninum infection in dogs from Romania. Veterinary Parasitology 188, 382-385.

Gondim, L. F., McAllister, M. M., Mateus-Pinilla, N. E., Pitt, W. C., Mech, L. D. and Nelson, M. E. (2004a). Transmission of Neospora caninum between wild and domestic animals. Fournal of Parasitology 90, 1361-1365.

Gondim, L. F., McAllister, M. M., Pitt, W. C. and Zemlicka, D. E. (2004b). Coyotes (Canis latrans) are definitive hosts of Neospora caninum. International Fournal for Parasitology 34, 159-161.

Gondim, L. F., Meyer, J., Peters, M., Rezende-Gondim, M. M., Vrhovec, M. G., Pantchev, N., Bauer, C., Conraths, F. J. and Schares, G. (2015). In vitro cultivation of Hammondia heydorni: generation of tachyzoites, stage conversion into bradyzoites, and evaluation of serologic cross-reaction with Neospora caninum. Veterinary Parasitology 210, 131-140.

Goździk, K., Wrzesień, R., Wielgosz-Ostolska, A., Bień, J., KozakLjunggren, M. and Cabaj, W. (2011). Prevalence of antibodies against Neospora caninum in dogs from urban areas in Central Poland. Parasitolgy Research 108, 991-996.

Hamilton, C. M., Gray, R., Wright, S. E., Gangadharan, B., Laurenson, K. and Innes, E. A. (2005). Prevalence of antibodies to Toxoplasma gondii and Neospora caninum in red foxes (Vulpes vulpes) from around the UK. Veterinary Parasitology 130, 169-173.

Hernandez, J., Risco, C. and Donovan, A. (2001). Association between exposure to Neospora caninum and milk production in dairy cows. Fournal of the American Veterinary Medical Association 219, 632-635.

Hughes, J. M., Thomasson, D., Craig, P. S., Georgin, S., Pickles, A. and Hide, G. (2008). Neospora caninum: detection in wild rabbits and investigation of co-infection with Toxoplasma gondii by PCR analysis. Experimental Parasitology 120, 255-260.

Ibrahim, H. M., Huang, P., Salem, T. A., Talaat, R. M., Nasr, M. I., Xuan, X. and Nishikawa, Y. (2009). Short report: prevalence of Neospora caninum and Toxoplasma gondii antibodies in northern Egypt. American Fournal of Tropical Medicine and Hygiene 80, 263-267.

Jakubek, E. B., Bröjer, C., Regnersen, C., Uggla, A., Schares, G. and Björkman, C. (2001). Seroprevalences of Toxoplasma gondii and Neospora caninum in Swedish red foxes (Vulpes vulpes). Veterinary Parasitology 102, $167-172$.

Jakubek, E. B., Farkas, R., Pálfi, V. and Mattsson, J. G. (2007). Prevalence of antibodies against Toxoplasma gondii and Neospora caninum in Hungarian red foxes (Vulpes vulpes). Veterinary Parasitology 144, 39-44. Jakubek, E. B., Mattsson, R., Mörner, T., Mattsson, J. G. and GavierWidén, D. (2012). Potential application of serological tests on fluids from carcasses: detection of antibodies against Toxoplasma gondii and Sarcoptes scabiei in red foxes (Vulpes vulpes). Acta Veterinaria Scandinavica 54, 1-5. King, J. S., Slapeta, J., Jenkins, D. J., Al-Qassab, S. E., Ellis, J. T. and Windsor, P. A. (2010). Australian dingoes are definitive hosts of Neospora caninum. International fournal for Parasitology 40, 945-950.

Kottek, M., Grieser, J., Beck, C., Rudolf, B. and Rubel, F. (2006). World Map of the Köppen-Geiger climate classification updated. Meteorologische Zeitschrift 15, 259-263.

Kuruca, L., Spasojevic-Kosic, L., Simin, S., Savovic, M., Laus, S. and Lalosevic, V. (2013) Neospora caninum antibodies in dairy cows and domestic dogs from Vojvodina, Serbia. Parasite 20, 40.

Machacova, T., Bártová, E., Sedlak, K., Budikova, M. and Piccirillo, A. (2015) Risk factors involved in transmission of Toxoplasma gondii and Neospora caninum infection in rabbit farms in Northern Italy. Annals of Agricultural and Environmental Medicine 22, $677-679$.

Maia, C., Cortes, H., Brancal, H., Lopes, A. P., Pimenta, P., Campino, L. and Cardoso, L. (2014). Prevalence and correlates of antibodies to Neospora caninum in dogs in Portugal. Parasite 21, 29.

Marco, I., Ferroglio, E., López-Olvera, J. R., Montané, J. and Lavín, S. (2008). High seroprevalence of Neospora caninum in the red fox (Vulpes vulpes) in the Pyrenees (NE Spain). Veterinary Parasitology 152, 321-324.

Mörner, T., Sandström, G. and Mattsson, R. (1988). Comparison of serum and lung extracts for surveys of wild animals for antibodies to Francisella tularensis biovar palaearctica. Fournal of Wildlife Diseases 24, 10-14. 
McAllister, M. M., Dubey, J. P., Lindsay, D. S., Jolley, W. R., Wills, R. A. and McGuire, A. M. (1998). Dogs are definitive hosts of Neospora caninum. International Fournal for Parasitology 28, 1473-1478. McInnes, L. M., Irwin, P., Palmer, D. G. and Ryan, U. M. (2006). In vitro isolation and characterization of the first canine Neospora caninum isolate in Australia. Veterinary Parasitology 137, 355-363.

Mineo, T. W., Silva, D. A., Costa, G. H., von Ancken, A. C., Kasper, L. H., Souza, M. A., Cabral, D. D., Costa, A. J. and Mineo, J. R. (2001). Detection of IgG antibodies to Neospora caninum and Toxoplasma gondii in dogs examined in a veterinary hospital from Brazil. Veterinary Parasitology 98, 239-245.

Murphy, T. M., Walochnik, J., Hass1, A., Moriarty, J., Mooney, J., Toolan, D., Sanchez-Miguel, C., O'Loughlin, A. and McAuliffe, A. (2007). Study on the prevalence of Toxoplasma gondii and Neospora caninum and molecular evidence of Encephalitozoon cuniculi and Encephalitozoon (Septata) intestinalis infections in red foxes (Vulpes vulpes) in rural Ireland. Veterinary Parasitology 146, 227-234.

Packham, A. E., Sverlow, K. W., Conrad, P. A., Loomis, E. F., Rowe, J. D., Anderson, M. L., Marsh, A. E., Cray, C. and Barr, B. C. (1998). A modified agglutination test for Neospora caninum: development, optimization, and comparison to the indirect fluorescent-antibody test and enzyme-linked immunosorbent assay. Clinical and Diagnostic Laboratory Immunology 5, 467-473.

Paré, J., Hietala, S. K. and Thurmond, M. C. (1995). Interpretation of an indirect fluorescent antibody test for diagnosis of Neospora sp. infection in cattle. Fournal of Veterinary Diagnostic Investigation 7, 273-275.

Płoneczka, K. and Mazurkiewicz, M. (2008). Seroprevalence of Neospora caninum in dogs in south-western Poland. Veterinary Parasitology 153, 168-171.

Regidor-Cerrillo, J., Pedraza-Diaz, S., Rojo-Montejo, S., VazquezMoreno, E., Arnaiz, I., Gomez-Bautista, M., Jimenez-Palacios, S., Ortega-Mora, L. M. and Collantes-Fernandez, E. (2010). Neospora caninum infection in stray and farm dogs: seroepidemiological study and oocyst shedding. Veterinary Parasitology 174, 332-335.

Robbe, D., Passarelli, A., Gloria, A., Di Cesare, A., Capelli, G., Iorio, R. and Traversa, D. (2016). Neospora caninum seropositivity and reproductive risk factors in dogs. Experimental Parasitology 164, 31-35.

Schaefer, J. J., White, H. A., Schaaf, S. L., Mohammed, H. O. and Wade, S. E. (2011). Modification of a commercial Toxoplasma gondii immunoglobulin $\mathrm{G}$ enzyme-linked immunosorbent assay for use in multiple animal species. Fournal of Veterinary Diagnostic Investigation 23 , 297-301.

Sergeant, E. S. G. (2016). Epitools epidemiological calculators. Ausvet Pty Ltd. http://epitools.ausvet.com.au.

Shkap, V., Reske, A., Pipano, E., Fish, L. and Baszler, T. (2002) Immunological relationship between Neospora caninum and Besnoitia besnoiti. Veterinary Parasitology 106, 35-43.

Silva, D. A., Lobato, J., Mineo, T. W. and Mineo, J. R. (2007) Evaluation of serological tests for the diagnosis of Neospora caninum infection in dogs: optimization of cut off titers and inhibition studies of cross-reactivity with Toxoplasma gondii. Veterinary Parasitology 143, $234-244$.

Sobrino, R., Dubey, J. P., Pabón, M., Linarez, N., Kwok, O. C., Millán, J., Arnal, M. C., Luco, D. F., López-Gatius, F., Thulliez, P., Gortázar, C. and Almería, S. (2008). Neospora caninum antibodies in wild carnivores from Spain. Veterinary Parasitology 155, 190-197.

Thompson, G., Canada, N., do Carmo Topa, M., Silva, E., Vaz, F. and Rocha, A. (2001). First confirmed case of Neospora canimum-associated abortion outbreak in Portugal. Reproduction in Domestic Animals 36, 309-312. Thurmond, M. C. and Hietala, S. K. (1996). Culling associated with Neospora caninum infection in dairy cows. American fournal of Veterinary Research 57, 1559-1562.

Thurmond, M. C. and Hietala, S. K. (1997). Effect of congenitally acquired Neospora caninum infection on risk of abortion and subsequen abortions in dairy cattle. American Fournal of Veterinary Research $\mathbf{5 8}$ $1381-1385$.

Trees, A. J., Guy, F., Tennant, B. J., Balfour, A. H. and Dubey, J. P. (1993). Prevalence of antibodies to Neospora caninum in a population of urban dogs in England. Veterinary Record 132, 125-126.

Uzeda, R. S., Costa, K. de S., Santos, S. L., Pinheiro, A. M., De Almeida, M. A., McAllister, M. M. and Gondim, L. F. (2007). Loss of infectivity of Neospora caninum oocysts maintained for a prolonged time. Korean Fournal of Parasitology 45, 295-299.

Václavek, P., Sedlák, K., Hůrková, L., Vodrázka, P., Sebesta, R. and Koudela, B. (2007). Serological survey of Neospora caninum in dogs in the Czech Republic and a long-term study of dynamics of antibodies. Veterinary Parasitology 143, 35-41.

Waap, H., Cardoso, R., Marcelino, E., Malta, J., Cortes, H. and Leitão, A. (2011). A modified agglutination test for the diagnosis of Besnoitia besnoiti infection. Veterinary Parasitology 178, 217-222.

Waap, H., Nunes, T., Vaz, Y. and Leitão, A. (2016). Serological survey of Toxoplasma gondii and Besnoitia besnoiti in a wildlife conservation area in southern Portugal. Veterinary Parasitology Regional Studies and Reports 34, 7-12.

Waller, T., Lyngset, A., Elvander, M. and Morein, B. (1980). Immunological diagnosis of encephalitozoonosis from post-mortem specimens. Veterinary Immunology and Immunopathology 1, 353-360.

Wang, S., Yao, Z., Zhang, N., Wang, D., Ma, J., Liu, S., Zheng, B., Zhang, B., Liu, K. and Zhang, H. (2016). Serological study of Neospora caninum infection in dogs in central China. Parasite 23, 25.

Wanha, K., Edelhofer, R., Gabler-Eduardo, C. and Prosl, H. (2005). Prevalence of antibodies against Neospora caninum and Toxoplasma gondii in dogs and foxes in Austria. Veterinary Parasitology 128, 189-193.

Yakhchali, M., Javadi, S. and Morshedi, A. (2010). Prevalence of antibodies to Neospora caninum in stray dogs of Urmia, Iran. Parasitology Research 106, 1455-1458.

Zhang, D., Wang, Z., Fang, R., Nie, H., Feng, H., Zhou, Y. and Zhao, J. (2010). Use of protein AG in an enzyme-linked immunosorbent assay for serodiagnosis of Toxoplasma gondii infection in four species of animals. Clinical and Vaccine Immunology 17, 485-486. 